\title{
An emerging role for microRNAs in NF1 tumorigenesis
}

\author{
Ashni Sedani, David N Cooper and Meena Upadhyaya*
}

\begin{abstract}
MicroRNAs (miRNAs) are a class of non-coding RNA, which have recently been shown to have a wide variety of regulatory functions in relation to gene expression. Since their identification nearly 20 years ago, miRNAs have been found to play an important role in cancer, including in neurofibromatosis type 1 (NF1)-associated tumours. NF1 is the most commonly inherited tumour predisposition syndrome and can lead to malignancy via the development of malignant peripheral nerve sheath tumours (MPNSTs). Although the mechanisms by which benign neurofibromas develop into MPNSTs still remain to be elucidated, it is becoming increasingly clear that miRNAs play a key role in this process and have the potential to be used as both diagnostic and prognostic markers of tumorigenesis.
\end{abstract}

Keywords: MicroRNAs, Neurofibromatosis type 1, Malignant peripheral nerve sheath tumours, Tumorigenesis

\section{Introduction}

miRNAs constitute a category of small RNAs, ranging between 19 and 25 nucleotides in length, which are generated from endogenous hairpin-shaped transcripts. They function predominantly as post-transcriptional regulators of gene expression by hybridizing to the $3^{\prime}$ untranslated regions ( $3^{\prime} \mathrm{UTRs}$ ) of target mRNA molecules $[1,2]$, leading to translational repression or cleavage of the target mRNA [3]. The first described miRNA, known as lin-4, was discovered in Caenorhabditis elegans by Lee et al. in 1993 [4]. This was later followed by the discovery of let-7 [5], which was found to be highly conserved across many different species [6], indicating the widespread existence of miRNAs in eukaryotes. More than 1,500 human miRNA sequences have been reported in the human genome to date (miRBase; http://www. mirbase.org/), of which $50 \%$ have been found to occur within clusters, targeting either the same or different genes within the same biological pathway [7]. It has become apparent that miRNAs regulate the expression of at least $30 \%$ of all protein-coding genes in mammalian genomes [8], underlining their likely role in human genetic disease. Novel techniques developed for the identification of miRNAs have been instrumental in the rapid

\footnotetext{
* Correspondence: upadhyaya@cardiff.ac.uk
Institute of Medical Genetics, School of Medicine, Cardiff University, Heath

* Correspondence: upadhyaya@cardiff.ac.uk
Institute of Medical Genetics, School of Medicine, Cardiff University, Heath Park, Cardiff CF14 4XN, UK
}

progress made by miRNA research. miRNAs play an important role in the development and progression of cancer. With an ever-increasing number of studies focusing on the roles of miRNAs in cancer, whether operating as oncogenes or tumour suppressor genes, our understanding of the way in which miRNAs function is steadily improving, and hence the number of potential therapeutic applications for miRNAs should also increase.

In this review, the structure, function and biogenesis of miRNA molecules are discussed in reference to the recent developments that focus upon the role of miRNAs in relation to neurofibromatosis type 1.

\section{miRNA biogenesis, export and function}

The process of miRNA biogenesis involves miRNA transcription, the transport of the miRNAs to the cytoplasm and subsequent maturation. miRNA biogenesis has been reviewed in detail by Ladomery et al. [9] and will not be specifically discussed here. However, the basic process has been summarised in Figure 1.

The mechanism by which mature miRNAs regulate gene expression depends upon the level of complementarity that exists between the miRNA and its target mRNA [17]. Gene silencing can be effected either by mRNA degradation or by inhibiting the mRNA from being translated. It has been shown that if there is complete complementarity between the miRNA and 
target mRNA sequence, then Argonaute 2, a member of the Argonaute protein family, can carry out strand selection and separation causing an RNA-induced silencing complex (RISC) to bind to its mRNA target, leading to mRNA degradation which in turn impacts upon translation [18]. If, however, the complementarity is imperfect, as seen in most cases, translational repression ensues [19]. Therefore, the main function of miRNAs appears to be in the context of gene regulation via mRNA degradation. Rarely, miRNAs can also bring about histone modification and DNA methylation of gene promoter

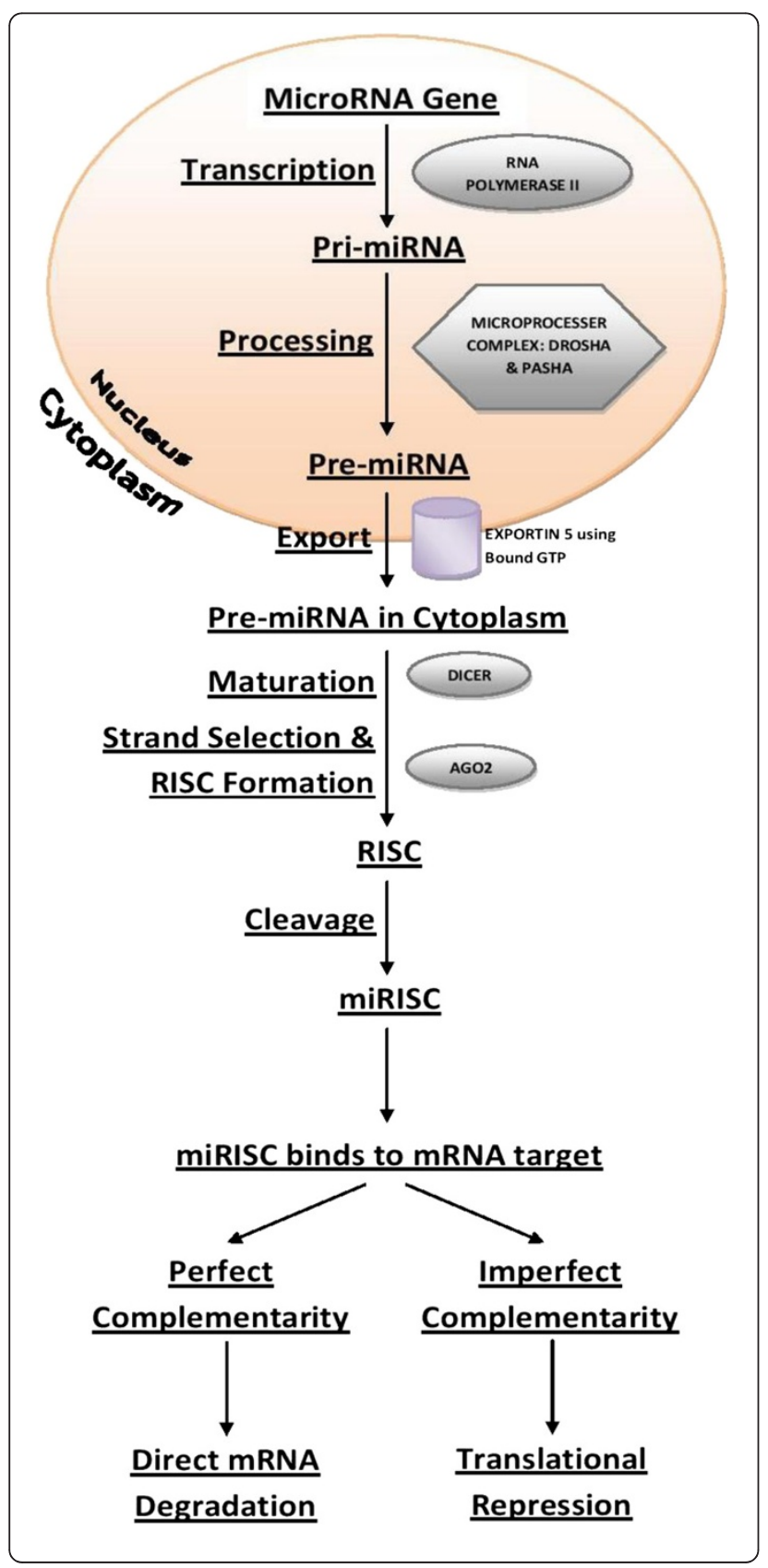

Figure 1 The flowchart highlights the processes involved in the following miRNA biogenesis: (1) The process begins inside the nucleus, where RNA polymerase II or III initiates the transcription of miRNA-coding genes to produce 'pri-microRNA's [10,11]. (2) A microprocessor complex comprising both Drosha, an RNase III class enzyme, and Pasha, identifies and cleaves pre-microRNAs generating pre-microRNAs [12-14]. (3) Pre-microRNA molecules are transferred to the cytoplasm through exportin-5-mediated transport, which uses GTP that is bound to the Ran protein. The function of exportin-5 is dependent upon the GTP-bound form of the Ran co-factor for specific binding to the corresponding substrates. Therefore, this process comprises the hydrolysis of Ran-GTP to Ran-GDP, via the Ran GTPase-activating protein in the cytoplasm $[15,16]$. (4) In the cytoplasm, Dicer acts to cleave pre-miRNA molecules and, with the action of Argonaute 2 which is required for miRNA-induced silencing, forms an

RNA-induced silencing complex (RISC) leading to the creation of a miRNA-induced silencing complex (miRISC). (5) Interaction between the miRNA and its target mRNA in the miRISC can cause either translational repression or miRNA degradation depending upon the degree of complementarity.

regions, thereby indirectly altering the expression of target genes $[20,21]$.

\section{Methodologies}

miRNA expression profiles can be used both to categorize different types of cancer and to identify miRNA markers that can help in making prognostic predictions [22]. Initially, northern blotting was used to detect pre-miRNAs and mature miRNAs and to provide information about the regulation of the enzymes involved in miRNA biogenesis [23]. Real-time polymerase chain reaction (PCR) and microarray techniques have also been tailored to detect the expression of premiRNAs and mature miRNAs using either SYBR Green dye or TaqMan probes (Sigma-Aldrich Corporation, St. Louis, MO, USA) [24]. Further, Liu et al. in 2004 [25] used oligonucleotide microchips to identify distinct miRNA expression patterns in breast cancer and B cell chronic lymphocytic leukaemia. Nevertheless, miRNA microarray techniques are constantly being improved; thus, Neely et al. in 2006 [26] developed modified oligonucleotide arrays where probes for each miRNA were designed and labelled with different fluorophores whereas Lu et al. in 2005 [27] used a flow cytometrybased method analysis to demonstrate expression of miRNAs from a range of different samples. Both methods allowed the quantification of miRNA expression, thereby making cancer diagnosis through miRNA analysis more specific and accurate. The advantage of using miRNAs as markers instead of mRNAs lies in their ability to aid the classification of poorly differentiated cancers, as evidenced by the study by Rosenfeld et al. in 2008 [28], suggesting that miRNAs can be used to correctly identify the tumour tissue of origin. 
The potential role of miRNAs in pathology has been studied by looking not only at their single nucleotide polymorphisms (SNPs) but also at their copy number variation $(\mathrm{CNV})$. Functional polymorphisms in the $3^{\prime}$ UTRs of miRNA genes have been reported to be associated with cancer by virtue of their altering gene expression. SNPs may occur in miRNA biogenesis pathway genes, primary miRNAs, pre-miRNAs or mature miRNA sequences and have the potential to affect the efficiency of miRNA binding to their target sites or alternatively can create or disrupt miRNA binding sites [29]. In a recent study, Gong et al. [30] identified 48 SNPs in human miRNA seed regions and a large number of SNPs in $3^{\prime}$ UTRs with the potential to either disturb or create miRNA target interactions. They confirmed the loss-offunction and gain-of-function SNPs by luciferase assay.

Zhang et al. in 2006 [31] found that a large proportion of loci containing miRNA genes exhibited somatic copy number alterations and, amongst the three cancer types, they identified 41 miRNAs with copy number changes. These miRNA copy number changes also correlated with the levels of miRNA expression in these cancers. High frequency copy number changes were also noted in the genes encoding Dicer (DICER1) and Argonaute 2 (EIF2C2), both of which are required for miRNA biogenesis. These findings are compatible with the view that somatic miRNA copy number changes are common in cancer and could potentially account for at least a proportion of the miRNA deregulation found in many tumour types. Using bioinformatic tools, Marcinkowska et al. in 2011 [32] have demonstrated that miRNA loci are under-represented in highly polymorphic and wellvalidated $\mathrm{CNV}$ regions. Thus, CNV-miRNAs represent functional variants of potential importance for genotype/ phenotype association studies.

\section{miRNAs in neurofibromatosis type 1}

Neurofibromatosis type 1 (NF1), a familial tumour predisposition syndrome, is characterised by the growth of benign and malignant tumours involving the peripheral and central nervous system. NF1 results from inactivating germline mutations of the NF1 gene located at 17q11.2 [33]. Most NF1 patients develop multiple benign cutaneous neurofibromas, with approximately $30 \%$ to $50 \%$ of patients also developing larger plexiform neurofibromas. About $10 \%$ of patients eventually develop malignant peripheral nerve sheath tumours (MPNSTs), which are aggressive tumours that pose significant diagnostic and therapeutic challenges. Half of all MPNSTs diagnosed occur in association with NF1, with affected patients exhibiting a poor prognosis. With no effective treatment available, radical surgery and chemo and radiotherapy are required to reduce tumour recurrence and metastasis and prolong patient survival.
The process of MPNST pathogenesis is poorly understood owing to its complex histopathology and the underlying molecular mechanisms. Biallelic NF1 gene inactivation is essential for tumour development. However, it is now known that additional molecular changes and the tumour micro-environment are associated with the progression of this type of tumour. There is currently no defined molecular signature for MPNST development. Constitutive activation of several critical cell signalling cascades also occurs in MPNSTs. Multidisciplinary collaborative efforts are clearly essential to fully decipher both the complex molecular basis of MPNST development and to define potential therapeutic targets.

A general characteristic of cancer cells is uncontrolled growth and, in many cases, miRNAs can either promote or suppress this growth. Previous investigations have shown that miRNAs have key functions in the development of cancer, in relation to a range of different cellular processes including cell differentiation, developmental control, neural development, cell proliferation, apoptosis [34,35] and organ development [3]. Thus, the role of a given miRNA in cancer pathogenesis can be categorised as being either of oncogene or tumour suppressor gene nature. Moreover, it is thought that $>50 \%$ of miRNAcoding genes are located in cancer-associated genomic regions or in fragile sites [36]. It is now known that miRNAs are associated with a range of different cancers, including chronic leukaemias, acute leukaemias and myelodysplastic syndromes, lymphomas, multiple myeloma, hepatocellular carcinoma, breast, lung and colon cancer, amongst others.

Several research groups have studied the role of miRNA in NF1-associated malignancy. Here we focus on miRNAs miR-29c, miR-34a, miR-214, miR-10b, miR204 and miR-21 which have previously been directly implicated in NF1 tumorigenesis (summarized in Table 1).

\section{miR-34a}

One of the earliest studies of miRNAs in NF1 was carried out by Subramanian et al. [37]. Their genome-wide

\begin{tabular}{|c|c|c|c|}
\hline miRNA & $\begin{array}{l}\text { Change in } \\
\text { expression in } \\
\text { MPNSTs }\end{array}$ & $\begin{array}{l}\text { Tumour suppressor } \\
\text { or oncogene role }\end{array}$ & Reference \\
\hline miR-34a & Down-regulated & Tumour suppressor & {$[37]$} \\
\hline miR-214 & Over-expressed & Oncogene & {$[37]$} \\
\hline miR-10b & Over-expressed & Oncogene & {$[37,38]$} \\
\hline miR-29c & Down-regulated & Tumour suppressor & [39] \\
\hline miR204 & Down-regulated & Tumour suppressor & {$[40]$} \\
\hline miRNA-21 & Over-expressed & Oncogene & [41] \\
\hline
\end{tabular}


transcriptome analyses revealed that the development of malignancy from neurofibroma to MPNST correlates with the loss of expression of a number of genes rather than an increase in expression. This subsequently led to miRNA expression profiling which demonstrated the down-regulation of miR-34a in most MPNSTs as compared to neurofibromas. This loss of miR-34a could contribute to the development of malignancy. miR-34 is known to be a direct target of p53 in a variety of neoplasms including colorectal carcinoma and neuroblastoma in which lower levels of this miRNA are associated with the suppression of apoptosis. Forced expression of miR-34a in MPNST cell lines that are deficient in miR-34a leads to increased apoptosis whereas the forced expression of p53 in the same cell line results in a similar effect, indicating that the expression of p53 results in apoptosis through a mechanism involving miR-34a. The study of Subramanian et al. in 2010 also revealed an increase in the expression levels of a further nine miRNAs, following induced expression of p53 in MPNSTs. Interestingly, six of these (including miR-638, miR-373, miR-492, miR-126, miR-140 and miR-491), have been shown to be involved in promoting tumorigenic processes such as invasion, proliferation and metastasis.

Using a systems biology approach, Lee et al. [42] identified a regulatory network which involved the E2F family: E2F7/E2F8 in several cell cycle-related gene modules. miR-34a over-expression was found to lead to increased activity of E2F7/E2F8 transcription factors and cell cycle genes. These transcription factors are disproportionately associated with DNA damage repair, cell growth and development [42,43], and the altered expression levels of this family of transcription factors has been noted in cancerous cells [44], indicating that miR34a could be a target for therapeutic intervention. As E2F transcription factors are involved in transcriptional regulation as well as in DNA repair and cell proliferation, it is possible that an alteration in the expression of activators and suppressors of E2F7 and E2F8 transcription may play a role in the development of MPNSTs. However, recent data by Presneau et al. [39] failed to confirm the work by Subramanian et al. [37] regarding miR-34a. This was deemed to be due either to differences in the methodologies used or to the use of different groups of patients based on differences in NF1 diagnostic criteria. Recent reports indicate that miR-34a has also been shown to act as a tumour suppressor through its dysregulation in a number of other carcinomas including glioblastoma multiforme tumours [45], breast cancer [46], head and neck squamous cell carcinoma [47] and osteosarcoma [48], suggesting that it could represent a significant gene target in cancer therapeutics.

\section{miR-214}

Subramanian et al. [37] identified miR-214 as having the highest expression level of all miRNAs screened in their study of NF1-MPNSTs. miR-214 had previously been shown to be expressed at an increased level in the blood of breast and ovarian cancer patients, indicating that it could be used as an indicator of malignancy [49,50]. Yang et al. [50] proposed that miR-214 induces cell survival and cisplatin resistance through targeting the $3^{\prime}$ UTR of the PTEN gene, which leads to downregulation of the PTEN protein and the activation of the Akt pathway, thereby promoting cell survival. More recently, Peng et al. [51] found that miR-214 can inhibit cancer cell proliferation and migration by targeting GALNT7. This is supported by data from Shih et al. [52], who showed that miR-214 down-regulation can contribute to tumour angiogenesis and is associated with increased tumour recurrence and a poor prognosis. In their study, Subramanian et al. [37] also identified a metastasis-promoting factor, TWIST1, as promoting expression of miR-214. TWIST1 had previously been noted to increase metastasis in a number of different carcinomas, but its exact role in NF1 tumorigenesis has not yet been elucidated. Taken together with the above data, it is suggested that TWIST1 may regulate miR-214 expression thereby contributing to tumorigenesis [53].

\section{miR-10b}

By inhibiting the expression of miR-10b in NF1-MPNSTs, Subramanian et al. [37] demonstrated decreased cell proliferation and migration, indicating an important function for miR-10b in the transformation of benign NF1-associated neurofibromas to MPNSTs. These workers also showed that the expression of miR-10b is considerably higher in NF1-MPNST cell lines, NF1-MPNST tumour tissues and primary Schwann cells by comparison with benign neurofibromas. This suggests that miR-10b could act as a biomarker to differentiate between NF1-MPNSTs and neurofibromas. miR-10b belongs to the miR-10 cluster of miRNAs and is highly conserved between different species. Its location within the Hox gene clusters suggests that it could share the same mechanisms of regulation as the Hox genes [54]. Supporting this notion that over-expressed miRNAs of the miR-10 family may play a role in cancer, miR-10b has also been found to be overexpressed in B cell chronic lymphocytic leukaemia [36] as well as in acute myeloid leukaemias associated with mutations in the NPM1 gene [55].

miR-10b expression has also been shown as enhanced by increased expression of TWIST1 in MPNST cells [56]. Chai et al. [38] have suggested that it is the increased expression of TWIST1 that may cause increased expression of miR-10b in the MPNSTs of NF1 patients. In their 
study, which compared MPNST cell lines from NF1 patients with those from sporadic tumours, Chai et al. [38] identified miR-10b, miR-155 and miR-335 as being over-expressed and Let-7a and Let-7b as being underexpressed in the NF1-MPNST cell lines. Further investigation showed that miR-10b reduced cell migration, invasion and proliferation. While inhibiting miR-155 did not correct the abnormal growth behaviour of NF1 MPNST cells, inhibiting miR-335 or enhancing let-7a expression partially corrected some abnormal growth properties of these tumour cells. These findings suggest that changes in miR-155 may represent a consequence of NF1 MPNST tumour formation, while changes in miR-335 and let-7 expression may contribute to progression of NF1 MPNSTs. These speculations are supported by the observation that $R A S$ and tenascin $C$ are deregulated in NF1 MPNSTs. Subsequently, these authors went on to demonstrate that miR-10b targets the NF1 mRNA $3^{\prime} \mathrm{UTR}$, thereby repressing the expression of neurofibromin protein. Therefore, it is suggested that miR-10b could specifically target neurofibromin to control NF1 tumorigenesis and progression. Irrespective of whether or neurofibromin is functional, as long as there is expression of the NF1 mRNA, it is possible for the miR-10b to target its $3^{\prime}$ UTR to suppress expression of neurofibromin protein. Chai et al. [38] also suggested that miR-10b could target other genes, and co-operate with other miRNAs such as miR-335 and let-7, to promote NF1 tumorigenesis and progression.

\section{miR-29c}

Presneau et al. [39] aimed to identify a molecular target to help discriminate between neurofibromas and MPNSTs. In their study of ten matched pairs of samples of MPNSTs and neurofibromas from NF1 patients, Presneau et al. [39] showed miR-210 to have been upregulated, and a series of miRNAs to have been down-regulated (miR-30e, miR-30c, miR-340, miR-139-5p, miR-29c and Let-7g) in MPNSTs. Of these miR-29c was the most down-regulated; the gene targets of miR-29c include COL1A1, COL21A1, COL5A2 and TDG, all of which were down-regulated in MPNSTs. This was confirmed using synthetic oligonucleotide mimics. Further assays showed increased migration and invasion of MPNST cells following treatment with a miR-29c mimic. Presneau et al. [39] postulated that the decreased expression levels of miR-29c are mediated by the activation of a hepatocyte growth factor receptor, CMET, which has been shown to be activated in MPNSTs. This hypothesis is supported by the findings of Kwiecinski et al. [57] who demonstrated that hepatocyte growth factor receptor can inhibit collagen synthesis by activating miR-29a and miR-29b. Together, these data suggest that miR-29c is regulated by the action of
cMET which, when activated, can stimulate miR-29 to control cell migration and invasion. Thus, miR-29c can act as a tumour suppressor and could potentially be used as a means to distinguish malignant from benign tumours. This suggestion has been borne out by findings in colorectal cancer, where analysis of mRNA expression profiles has indicated that miR-29c can predict the recurrence of colorectal cancer [58], and in hepatitis $B$ virus-related hepatocellular carcinoma, where miR29c inhibits cell proliferation and promotes apoptosis [59].

\section{miR-204}

Recently, Gong et al. [40] reported that miR-204 contributes to the growth of MPNSTs, particularly in NF1. They postulated that this miRNA plays an important role in the carcinogenic process as it is found in cancerassociated regions of the genome and has previously been shown to be subject to high-frequency loss of heterozygosity in tumours [60]. miR-204 has also been found to act as a tumour suppressor gene in various other tumours including breast, kidney and prostate cancers [61]. This study demonstrated that the expression of miR-204 is down-regulated in tissue, which is derived from both NF1- and non-NF1-related tumours. By inducing the expression of miR-204 in MPNSTs of both NF1 and non-NF1 origin, the abnormal cellular characteristics were reversed and cell proliferation was reduced. Specifically in an NF1-related tumour cell line, induced expression of miR-204 resulted in decreased progression of malignancy and tumour development. Further bioinformatic analysis revealed that miR-204 targets $H M G A 2$, a gene that regulates RAS signalling, suggesting that miR-204 may also contribute indirectly to the development of malignancy. It was also found that HMGA2 expression is inhibited by miR-204, revealing an alternative pathway for tumour progression. It is still not clear whether miR-204 alone is sufficient to promote carcinogenesis in MPNSTs, as earlier studies have indicated that p53 inactivation and subsequent loss of expression of miR-34a may contribute to MPNST development [37]. Although these results have only been confirmed in vitro, miR-204 could potentially act as a biomarker for cancer diagnosis as well as an effective target for the development of therapeutic treatment.

\section{miR-21}

In a recent study, Itani et al. [41] analysed a panel of 12 MPNSTs, 11 neurofibromas, five normal nerves and three MPNST cell lines by mRNA expression profiling. The expression of miR-21 was significantly higher in MPNSTs than in the neurofibromas or MPNST cell lines. Transfection of miR-21 inhibitor significantly increased caspase activity $(p<0.001)$ and suppressed cell growth $(p<0.05)$ while upregulating the level of PDCD4 
protein. Hence, these results indicate that miR-21 is likely to play an important role in MPNST progression through its target $P D C D 4$.

\section{NF1 microdeletions}

It has been estimated that $5 \%$ of NF1 patients possess a germline 1.4-Mb microdeletion [62]. This results from the unequal recombination between two homologous NF1 low copy-number repeats [63]. NF1-microdeleted patients have an increased risk of developing MPNSTs [64]. They also appear to exhibit a more severe clinical phenotype in comparison to individuals with intragenic NF1 mutations [65]. Analysis of the NF1 microdeleted region reveals that it contains a minimum of 16 protein coding genes, four pseudogenes and two microRNAs [66]. A recent study by Pasmant et al. [67] looked at the two miRNAs located within the 1.4-Mb microdeleted region in a set of MPNSTs and benign neurofibromas of NF1 microdeleted patients. They found that the two miRNA genes (MIR3652 and MIR193A at 17q11.2 encoding miR-365-2 and miR-193a, respectively) displayed no differences in the expression between the tumour types, despite miR-193a having been previously categorized as a tumour suppressor in oral squamous cell carcinoma [68] and despite miR-365-2 having been identified as having an anti-proliferative role in colon cancer [69]. Further study will be required to assess the possible role of these two miRNAs in NF1 tumorigenesis.

\section{NF1-phaeochromocytomas}

Tömböl et al. [70] analysed the expression pattern of miRNAs in patients with NF1-associated pheochromocytomas by real-time quantitative reverse-transcription PCR. The results of their study revealed 16 differentially expressed miRNAs; their pathway analysis suggested that Notch- and G-protein-coupled receptor signalling may be involved in tumour recurrence. These authors also demonstrated the successful use of formalin-fixed paraffin-embedded samples for the analysis of miRNAs in phaeochromocytomas.

\section{Epigenetic regulation of microRNAs in cancer}

DNA methylation in the $5^{\prime}$ regulatory regions of genes is a major epigenetic mechanism. The role of aberrant DNA hypermethylation in the regulation of miRNA expression in human cancer has also been explored [71]. This study identified 122 miRNAs which were reported to be epigenetically regulated in 23 cancer types. Human oncomirs (miRNAs) with a role in cancer are designated as oncogenic miRNAs or oncomirs. High methylation levels compared to the protein-coding genes and at least half of the epigenetically regulated miRNAs were involved with different cancer types.
Both DNA methylation and mRNA regulation can suppress gene expression and their corresponding gene product. $\mathrm{Su}$ et al. [72] demonstrated that miRNAs tend to target genes with a low level of DNA methylation level in their promoter regions. They also found that miRNA target sites were significantly enriched in genes located in differentially methylated regions or partially methylated domains and that cancer genes tend to be characterized by a low level of methylation and more miRNA target sites.

\section{miRNAs as prognostic and diagnostic biomarkers}

Dysregulation of miRNAs is fundamental to the pathogenesis of many cancers. miRNAs that regulate the expression of tumour suppressor genes and oncogenes are candidates for use in targeted therapies [73]. An improved understanding of the underlying molecular mechanisms is still required for many cancers so as to make possible the development of effective targeted therapies. Krutzfeldt et al. [74] created chemically modified antagomirs, molecules which are complementary to miRNAs and which provide a useful way of silencing specific miRNAs in vivo. Just as one miRNA may regulate multiple targets, one target may also be regulated by a number of different miRNAs. Hence, specificity is an important factor to consider in designing a therapeutic approach.

miRNAs are increasingly being identified as useful diagnostic and prognostic markers. One example of this is in hepatocellular carcinoma (HCC) in which it has been shown that low levels of miR-26 can be indicative of a poor prognosis [75]. These patients have also been shown to benefit from a specific type of interferon- $\alpha$ therapy, showing that miR-26 can be used to identify HCC patients who would be more likely to respond well to this type of treatment. miRNAs can also be shown to overcome drug resistance when targeted, in chemo-resistance [76] and resistance to anti-oestrogenic therapies $[77,78]$, demonstrating the range of different treatment methods to which miRNAs can contribute. miRNA delivery may be used to counteract carcinogenesis. miRNAs are reliable biomarkers for testing the efficiency of chemoprevention and may be used to counteract carcinogenesis [79].

As well as individual miRNAs being able to act as biomarkers and therapeutic targets, Han et al. [80], have shown that the three genes involved in miRNA biogenesis, namely DICER1, DROSHA and XPO5 (exportin 5), have also been shown to have therapeutic potential, at least in the case of bladder urothelial carcinoma. These genes are vital for miRNA development, and their silencing results in the inhibition of cell proliferation and apoptosis. Han et al. [80] showed that all three genes were up-regulated and had higher expression in high- 
grade carcinomas than low-grade carcinomas. These differential expression patterns indicate that DICER1, DROSHA and XPO5 could play active roles in carcinogenesis.

The use of miRNAs as useful biomarkers of tumorigenesis is supported by the finding that they are secreted into bodily fluids [81] and, hence, are circulating around the body so that they can be easily and accurately observed by means of microarray and quantitative PCR methods, allowing their detection to be both sensitive and specific [82]. There are already clinical diagnostic tests available that use miRNAs as biomarkers, such as the ProOnc TumorSource Dx, a proprietary test offered by Prometheus Labs (San Diego, CA, USA) (http://www. prometheuslabs.com), that determines the expression levels of 48 different miRNA biomarkers in a tissue sample, from which the results are used to determine the tissue of origin of metastatic cancer.

\section{Conclusions}

The discovery of miRNAs nearly 20 years ago introduced us to a new regulatory mechanism enabling a better understanding of the molecular pathogenesis of cancers. Dysregulation of miRNAs is fundamental to the pathogenesis of many cancers. miRNAs have the potential to target as many as several hundred genes simultaneously making them attractive prognostic biomarkers and therapeutic targets in cancer. miRNAs are not only involved in tumour progression, but also play a role in cancer invasion, metastasis, epigenetic alterations, chemo-resistance and radio-resistance. Although research on the role of miRNAs in NF1 tumorigenesis is still in its infancy, the experimental data obtained so far indicate that a number of miRNAs may be involved in NF1 tumorigenesis, including miR-29c, miR-34a, miR-214, miR-10b, miR-204 and miR-21. However, we lack an understanding of how different miRNAs identified in NF1 tumours might interact with neurofibromin and other tumour-associated proteins and whether these miRNAs can be linked to specific cancer signalling pathways. miRNAs involved in regulating the expression of oncogenes and tumour suppressor genes are candidates for targeted therapy for NF1 tumours. Therefore, it is hoped that the study of these small RNAs will eventually make a significant difference in treating NF1, at least to delay, if not entirely eliminate, the onset of tumorigenesis. The identification not only of differentially expressed microRNAs in tumours but also their target genes is providing new avenues for therapeutic approaches. As with any new therapeutic approach, there are of course many obstacles to be overcome before miRNAs can be used in clinical practise. However, it appears to present a very promising therapeutic avenue.
Competing interests

The authors declare that they have no competing interests.

\section{Authors' contributions}

AS contributed to the compilation of the first draft, DNC and MU improved the manuscript. All authors read and approved the final manuscript.

Received: 24 August 2012 Accepted: 26 September 2012 Published: 17 November 2012

\section{References}

1. Ambros V: The functions of animal microRNAs. Nature 2001, 431:350-355

2. Bartel DP: MicroRNAs: genomics, biogenesis, mechanism and function. Cell 2004, 116:281-297.

3. Lai EC: MicroRNAs are complementary to $3^{\prime} U T R$ sequence motifs that mediate negative post-transcriptional regulation. Nat Genet 2002, 30:363-364

4. Lee $R C$, Feinbaum RL, Ambros V: The $C$. elegans heterochronic gene lin-4 encodes small RNAs with antisense complementarity to lin-14. Cell 1993, 75:843-854.

5. Reinhart BJ, Slack FJ, Basson M, Pasquinelli AE, Bettinger JC, Rougvie AE, Horvitz HR, Ruvkun G: The 21-nucleotide let-7 RNA regulates developmental timing in Caenorhabtidis elegans. Nature 2000, 403:901-906.

6. Pasquinelli AE, Reinhart BJ, Slack FJ, Martindale MQ, Kuroda MI, Maller B, Hayward DC, Ball EE, Degnan B, Muller P, Spring J, Srinivasan A, Fishman M, Finnerty J, Corbo J, Levine M, Leahy P, Davidson E, Ruvkun G: Conservation of the sequence and temporal expression of Let-7 heterochronic regulatory RNA. Nature 2000, 408:86-89.

7. Yu J, Wang F, Yang GH, Wang FL, Ma YN, Du ZW, Zhang JW: Human microRNA clusters: genomic organization and expression profile in leukemia cell lines. Biochem Biophys Res Commun 2006, 13:59-68.

8. Sayed D, Abdellatif M: MicroRNAs in development and disease. Physio/ Rev 2011, 91:827-887.

9. Ladomery MR, Maddocks DG, Wilson ID: MicroRNAs: their discovery, biogenesis, function and potential use as biomarkers in non-invasive prenatal diagnostics. Int J Mol Epidemiol Genet 2011, 2:253-260.

10. Lee $Y$, Jeon $K$, Lee JT, Kim S, Kim VN: MicroRNA maturation: stepwise processing and subcellular localisation. EMBO J 2002, 23:4051-4060.

11. Zeng $Y, Y i R$, Cullen BR: Recognition and cleavage of primary microRNA precursors by the nuclear processing enzyme Drosha. EMBO J 2005, 24:138-148.

12. Denli AM, Tops BBJ, Plasterk RHA, Ketting RF, Hannon GJ: Processing of primary microRNAs by the microprocessor complex. Nature 2004, 432:231-235.

13. Gregory RI, Yan KP, Amuthan G, Chendrimada T, Doratotaj B, Cooch N, Shiekhatter R: The microprocessor complex mediates the genesis of microRNAs. Nature 2004, 432:235-240.

14. Landthaler M, Yalcin A, Tuschl T: The human DiGeorge syndrome critical region gene 8 and its D. melanogaster homolog are required for miRNA biogenesis. Curr Biol 2004, 14:2162-2167.

15. Yi R, Qin Y, Macara IG, Cullen BR: Exportin-5 mediates the nuclear export of pre-microRNAs and short hairpin RNAs. Genes Dev 2003, 17:3011-3016.

16. Lund E, Guttinger S, Calado A, Dahlberg JE, Kutay U: Nuclear export of microRNA precursors. Science 2004, 303:95-98.

17. Hwang HW, Mendell JT: MicroRNAs in cell proliferation, cell death and tumourigenesis. Br J Cancer 2006, 94:776-780.

18. Matranga C, Tomari Y, Shin C, Bartel DP, Zamore PD: Passenger-strand cleavage facilitates assembly of siRNA into Ago2-containing RNA enzyme complexes. Cell 2005, 123:607-620.

19. Winter J, Jung S, Keller S, Gregory Rl, Diederichs S: Many roads to maturity: microRNA biogenesis pathways and their regulation. Nat Cell Biol 2009, 11:228-234.

20. Tan G, Shi Y, Wu ZH: MicroRNA-22 promotes cell survival upon UV radiation by repressing PTEN. Biochem Biophys Res Commun 2012, 2012 (417):546-551.

21. Hawkins PG, Morris KV: RNA and transcriptional modification of gene expression. Cell Cycle 2008, 7:602-607.

22. Esquela-Kerscher A, Slack FJ: Oncomirs-microRNAs with a role in cancer. Nat Rev Cancer 2006, 6:259-269. 
23. Hammond SM: MicroRNA detection comes of age. Nat Methods 2006, 3:12-13.

24. Chen C, Ridzon DA, Broomer AJ, Zhou Z, Lee DH, Nguyen JT, Barbisin M, Xu NL, Mahuvakar VR, Andersen MR, Lao KQ, Livak KJ, Guegler KJ: Real-time quantification of microRNAs by stem-loop RT-PCR. Nucleic Acids Res 2005, 33:e179.

25. Liu CG, Calin GA, Meloon B, Gamliel N, Sevignani C, Ferracin M, Dumitru CD, Shimizu M, Zupo S, Dono M, Alder H, Bullrich F, Negrini M, Croce CM: An oligonucleotide microchip for genome-wide microRNA profiling in human and mouse tissues. Proc Nat Acad Sci USA 2004, 101:9740-9744.

26. Neely LA, Patel S, Garver J, Gallo M, Hackett M, McLaughlin S, Nadel M, Harris J, Gullans S, Rooke J: A single-molecule method for the quantitation of microRNA gene expression. Nat Methods 2006, 3:41-46.

27. Lu J, Getz G, Miska EA, Alvarez-Saavedra E, Lamb J, Peck D, Sweet-Cordero A, Ebert BL, Mak RH, Ferrando AA, Downing JR, Jacks T, Horvitz HR, Golub TR: MicroRNA expression profiles classify human cancers. Nature 2005, 435:834-838.

28. Rosenfeld N, Aharonov R, Meiri E, Rosenwald S, Spector Y, Zepeniuk M, Benjamin H, Shabes N, Tabak S, Levy A, Lebanony D, Goren Y, Silberschein E, Targan N, Ben-Ari A, Gilad S, Sion-Vardy N, Tobar A, Feinmesser M, Kharenko O, Nativ O, Nass D, Perelman M, Yosepovich A, Shalmon B, PolakCharcon S, Fridman E, Avniel A, Bentwich I, et al: MicroRNAs accurately identify cancer tissue origin. Nat Biotechnol 2008, 26:462-469.

29. Slaby O, Bienertova-Vasku J, Svoboda M, Vyzula R: Genetic polymorphisms and microRNAs: new direction in molecular epidemiology of solid cancer. J Cell Mol Med 2012, 16:8-21.

30. Gong J, Tong Y, Zhang HM, Wang K, Hu T, Shan G, Sun J, Guo AY: Genomewide identification of SNPs in microRNA genes and the SNP effects on microRNA target binding and biogenesis. Hum Mutat 2012, 33:254-263.

31. Zhang L, Huang J, Yang N, Greshock J, Megraw MS, Giannakakis A, Liang S, Naylor TL, Barchetti A, Ward MR, Yao G, Medina A, O'brien-Jenkins A, Katsaros D, Hatzigeorgiou A, Gimotty PA, Weber BL, Coukos G: microRNAs exhibit high frequency genomic alterations in human cancer. Proc Natl Acad Sci USA 2006, 103:9136-9141.

32. Marcinkowska M, Szymanski M, Krzyzosiak WJ, Kozlowski P: Copy number variation of microRNA genes in the human genome. BMC Genomics 2011, 12:183.

33. Upadhyaya M: Genetic basis of tumorigenesis in NF1 malignant peripheral nerve sheath tumors. Front Biosci 2011, 16:937-951.

34. Cheng AM, Byrom MW, Shelton J, Ford LP: Antisense inhibition of human miRNAs and indications for involvement of miRNA in cell growth and apoptosis. Nucleic Acids Res 2005, 33:1290-1297.

35. Cimmino A, Calin GA, Fabri M, lorio MV, Ferracin M, Shimizu M, Wojcik SE, Aqelin Rl, Zupo S, Dono M, Rassenti L, Alder H, Volinia S, Liu CG, Kipps TJ, Negrini M, Croce CM: miR-15 and miR-16 induce apoptosis by targeting BCL2. Proc Natl Acad Sci USA 2005, 102:13944-13949.

36. Calin GA, Sevignani C, Dumitru CD, Hyslop T, Noch E, Yendamuri S, Shimizu M, Rattan S, Bullrich F, Negrini M, Croce CM: Human microRNA genes are frequently located at fragile sites and genomic regions involved in cancers. Proc Natl Acad Sci USA 2004, 101:2999-3004.

37. Subramanian S, Thayanithy $\mathrm{V}$, West RB, Lee $\mathrm{CH}$, Beck AH, Zhu S, Downs-Kelly E, Montgomery K, Goldblum JR, Hogendoorn PC, Corless CL, Oliveira AM, Dry SM, Nielsen TO, Rubin BP, Fletcher JA, Fletcher CD, van de Rijn M: Genome-wide transcriptome analyses reveal p53 inactivation mediated loss of miR-34a expression in malignant peripheral nerve sheath tumours. J Pathol 2010, 220:58-70.

38. Chai G, Liu N, Ma J, Li H, Oblinger JL, Prahalad AK, Gong M, Chang LS, Wallace M, Muir D, Guha A, Phipps RJ, Hock JM, Yu X: MicroRNA-10b regulates tumourigenesis in neurofibromatosis type 1. Cancer Sci 2010, 101:1997-2004

39. Presneau N, Eskandarpour MS, Henderson S, Halai D, Tirabosco R, Flanagan AM: Micro-RNA profiling of peripheral nerve sheath tumours identifies miR-29c as a tumour suppressor gene involved in tumour progression. Br J Cancer 2012, doi:10.1038/bjc.2012.518.

40. Gong M, Ma J, Li M, Zhou M, Hock JM, Yu X: MicroRNA-204 critically regulates carcinogenesis in malignant peripheral nerve sheath tumors. Neuro Oncol 2012, 14:1007-1017.

41. Itani S, Kunisada T, Morimoto Y, Yoshida A, Sasaki T, Ito S, Ouchida M, Sugihara S, Shimizu K, Ozaki T: MicroRNA-21 correlates with tumorigenesis in malignant peripheral nerve sheath tumor (MPNST) via programmed cell death protein 4 (PDCD4). J Cancer Res Clin Oncol 2012, 138:1501-1509.
42. Lee Ming J, Choji H, Galas DJ, Wang K: The systems biology of neurofibromatosis type 1 - critical roles for microRNA. Exp Neurol 2012, 235:464-464.

43. Lammens T, Li J, Leone G, De Veylder L: Atypical E2Fs: new players in the E2F transcription factor family. Trends Cell Biol 2009, 19:111-118.

44. Reimer D, Sadr S, Wiedemair A, Stadlmann S, Concin N, Hofstetter G, MüllerHolzner E, Marth C, Zeimet AG: Clinical relevance of E2F family members in ovarian cancer - an evaluation in a training set of 77 patients. Clin Cancer Res 2007, 13:144-151.

45. Yin D, Ogawa S, Kawamata N, Leiter A, Ham M, Li D, Doan NB, Said JW, Black KL, Koeffler PH: miR-34a functions as a tumor suppressor modulating EGFR in glioblastoma multiforme. Oncogene 2012, 10:1038.

46. Li L, Yuan L, Luo J, Gao J, Guo J, Xie X: MiR-34a inhibits proliferation and migration of breast cancer hrough down-regulation of Bcl-2 and SIRT1. Clin Exp Med 2012, doi:10.1007/s10238-012-0186-5.

47. Kumar B, Yadav A, Lang J, Teknos TN, Kumar P: Dysregulation of microRNA-34a expression in head and neck squamous cell carcinoma promotes tumor growth and tumor angiogenesis. PLoS One 2012, 7:e37601.

48. Yan K, Gao J, Yang T, Ma Q, Qiu X, Fan Q, Ma B: MicroRNA-34a inhibits the proliferation and metastasis of osteosarcoma cells both in vitro and in vivo. Plos One 2012, 7:e33778.

49. Schwarzenbach H, Milde-Langosch K, Steinbach B, Müller V, Pantel K: Diagnostic potential of PTEN-targeting miR-214 in the blood of breast cancer patients. Breast Cancer Res Treat 2012, 134:933-941.

50. Yang H, Kong W, He L, Zhao JJ, O'Donnell JD, Wang J, Wenham RM, Coppola D, Kruk PA, Nicosia SV, Cheng JQ: MicroRNA expression profiling in human ovarian cancer: miR-214 induces cell survival and cisplatin resistance by targeting PTEN. Cancer Res 2008, 68:425-433.

51. Peng RQ, Wan HY, Li HF, Liu M, Li X, Tang H: MicroRNA-214 suppresses growth and invasiveness of cervical cancer cells by targeting UDP- $N$ acetyl-a-D-galactosamine:polypeptide $\mathrm{N}$-acetylgalactosaminyltransferase 7. J Biol Chem 2012, 287:14301-14309.

52. Shih TC, Tien YJ, Wen CJ, Yeh TS, Yu MC, Huang CH, Lee YS, Yen TC, Hsieh SY: MicroRNA-214 downregulation contributes to tumor angiogenesis via inducing secretion of hepatoma-derived growth factor in human hepatoma. J Hepatol 2012, 57:584-591.

53. Lee YB, Bantounas I, Lee DY, Phylactou L, Caldwell MA, Uney JB: Twist-1 regulates the miR-199a/214 cluster during development. Nucleic Acids Res 2009, 1:123-128.

54. Tanzer A, Amemiya CT, Kim CB, Stadler PF: Evolution of microRNAs located within Hox gene clusters. J Exp Zool B Mol Dev Evol 2005, 304:75-85.

55. Garzon R, Garofalo M, Martelli MP, Briesewitz R, Wang L, FernandezCymering C, Volinia S, Liu CG, Schnittger S, Haferlach T, Liso A, Diverio D, Mancini M, Meloni G, Foa R, Martelli MF, Mecucci C, Croce CM, Falini B: Distinctive microRNA signature of acute myeloid leukemia bearing cytoplasmic mutated nucleophosmin. Proc Natl Acad Sci USA 2008, 105:3945-3950.

56. Ma L, Teruya-Feldstein J, Weinberg RA: Tumour invasion and metastasis initiated by microRNA-10b in breast cancer. Nature 2007, 449:682-688.

57. Kwiecinski M, Noetel A, Elfimova N, Trebicka J, Schievenbusch S, Strack I, Molnar L, von Brandenstein M, Töx U, Nischt R, Coutelle O, Dienes HP, Odenthal M: Hepatocyte growth factor (HGF) inhibits collagen I and IV synthesis in hepatic stellate cells by miRNA-29 induction. PLoS One 2011, 6:e24568.

58. Kuo TY, Hsi E, Yang IP, Tsai PC, Wang JY, Juo SH: Computational analysis of mRNA expression profiles identifies microRNA-29a/c as predictor of colorectal cancer early recurrence. PLoS One 2012, 7:e31587.

59. Wang CM, Wang Y, Fan CG, Xu FF, Sun WS, Liu YG, Jia JH: miR-29c targets TNFAIP3, inhibits cell proliferation and induces apoptosis in hepatitis B virus-related hepatocellular carcinoma. Biochem Biophys Res Commun 2011, 411:586-592.

60. Bauer VL, Braselmann H, Henke M, Mattern D, Walch A, Unger K, Baudis M, Lassmann S, Huber R, Wienberg J, Werner M, Zitzelsberger HF: Chromosomal changes characterize head and neck cancer with poor prognosis. J Mol Med 2008, 86:1353-1365.

61. Wang FE, Zhang C, Maminishkis A, Dong L, Zhi C, Li R, Zhao J, Majerciak V, Gaur AB, Chen S, Miller SS: MicroRNA-204/211 alters epithelial physiology. FASEB J 2010, 24:1552-1571. 
62. Kluwe L, Siebert R, Gesk S, Friedrich RE, Tinschert S, Kehrer-Sawatzki H, Mautner VF: Screening 500 unselected neurofibromatosis 1 patients for deletions of the NF1 gene. Hum Mutat 2004, 23:111-116.

63. Dorschner MO, Sybert VP, Weaver M, Pletcher BA, Stephens K: NF1 microdeletion breakpoints are clustered at flanking repetitive sequences. Hum Mol Genet 2000, 9:35-46.

64. De Raedt T, Brems H, Lopez-Correa C, Vermeesch JR, Marynen P, Legius E: Genomic organization and evolution of the NF1 microdeletion region. Genomics 2004, 84:346-360.

65. Upadhyaya M, Ruggieri M, Maynard J, Osborn M, Hartog C, Mudd S, Penttinen M, Cordeiro I, Ponder M, Ponder BAJ, Krawczak M, Cooper DN: Gross deletions of the neurofibromatosis type 1 (NF1) gene are predominantly of maternal origin and commonly associated with a learning disability, dysmorphic features and developmental delay. Hum Genet 1998, 102:591-597.

66. Jenne DE, Tinschert S, Dorschner MO, Hameister H, Stephens K, KehrerSawatzki H: Complete physical map and gene content of the human NF1 tumour suppressor region in human and mouse. Genes Chrom Cancer 2003, 37:111-120.

67. Pasmant E, Masliah-Planchon J, Lévy P, Laurendeau I, Ortonne N, Parfait B, Valeyrie-Allanore L, Leroy $K$, Wolkenstein $P$, Vidaud $M$, Vidaud D, Bièche I: Identification of genes potentially involved in the increased risk of malignancy in NF1-microdeleted patients. Mol Med 2011, 17:79-87.

68. Kozaki K, Imoto I, Mogi S, Omura K, Inazawa J: Exploration of tumoursuppressive microRNAs silenced by DNA hypermethylation in oral cancer. Cancer Res 2008, 68:2094-2105.

69. Nie J, Liu L, Zheng W, Chen L, Wu X, Xu Y, Du X, Han W: microRNA-365, down-regulated in colon cancer, inhibits cell cycle progression and promotes apoptosis of colon cancer cells by probably targeting cyclin D1 and Bcl-2. Carcinogenesis 2012, 33:220-225.

70. Tömböl Z, Eder K, Kovács A, Szabó PM, Kulka J, Likó I, Zalatnai A, Rácz G, Tóth M, Patócs A, Falus A, Rácz K, Igaz P: MicroRNA expression profiling in benign (sporadic and hereditary) and recurring adrenal pheochromocytomas. Mod Pathol 2010, 23:1583-1595.

71. Kunej T, Godnic I, Ferdin J, Horvat S, Dovc P, Calin GA: Epigenetic regulation of microRNAs in cancer: an integrated review of literature. Mutat Res 2011, 717:77-84.

72. Su Z, Xia J, Zhao Z: Functional complementation between transcriptional methylation regulation and post-transcriptional microRNA regulation in the human genome. BMC Genomics 2011, 5:S15.

73. Nana-Sinkam SP, Croce CM: MicroRNAs as therapeutic targets in cancer. Transl Res 2011, 157:216-225

74. Krutzfeldt J, Rajewsky N, Braich R, Rajeev KG, Tuschl T, Manoharan M, Stoffel M: Silencing of microRNAs in vivo with 'antagomirs'. Nature 2005, 438:685-689.

75. Ji J, Shi J, Budhu A, Yu Z, Forgues M, Roessler S, Ambs S, Chen Y, Meltzer PS, Croce CM, Qin LX, Man K, Lo CM, Lee J, Ng IO, Fan J, Tang ZY, Sun HC, Wang XW: MicroRNA expression, survival, and response to interferon in liver cancer. N Engl J Med 2009, 361:1437-1447.

76. Meng F, Henson R, Lang M, Wehbe H, Maheshwari S, Mendell JT, Jiang J, Schmittgen TD, Patel T: Involvement of human micro-RNA in growth and response to chemotherapy in human cholangiocarcinoma cell lines. Gastroenterology 2006, 2006(130):2113-2129.

77. Miller TE, Ghoshal K, Ramaswamy B, Roy S, Datta J, Shapiro CL, Jacob S, Majumder S: MicroRNA-221/222 confers tamoxifen resistance in breast cancer by targeting p27Kip1. J Biol Chem 2008, 283:29897-29903.

78. Zhao JJ, Lin J, Yang H, Kong W, He L, Ma X, Coppola D, Cheng JQ: MicroRNA$221 / 222$ negatively regulates estrogen receptor alpha and is associated with tamoxifen resistance in breast cancer. J Biol Chem 2008, 283:31079-31086.

79. Izzotti A: Molecular medicine and the development of cancer chemopreventive agents. Ann N Y Acad Sci 2012, 1259:26-32.

80. Han Y, Liu Y, Gui Y, Cai Z: Inducing cell proliferation inhibition and apoptosis via silencing Dicer, Drosha, and Exportin 5 in urothelial carcinoma of the bladder. J Surg Oncol 2012, doi:10.1002/jso.23214. Epub ahead of print.

81. Steer CJ, Subramanian S: Circulating microRNAs as biomarkers: a new frontier in diagnostics. Liver Transpl 2012, 18:265-269.

82. Ajit SK: Circulating microRNAs as biomarkers, therapeutic targets, and signaling molecules. Sensors (Basel) 2012, 12:3359-3369.

\section{Submit your next manuscript to BioMed Central and take full advantage of:}

- Convenient online submission

- Thorough peer review

- No space constraints or color figure charges

- Immediate publication on acceptance

- Inclusion in PubMed, CAS, Scopus and Google Scholar

- Research which is freely available for redistribution 